Stefan Armonat and Andreas Pfnür

\title{
Asset allocation versus entrepreneurial decisions in real estate investment
}

Arbeitsbereich öffentliche Wirtschaft am Fachbereich Wirtschaftswissenschaften der Universität Hamburg

No. 030

November 2003 


\title{
Asset allocation versus entrepreneurial decisions in real estate investment
}

\author{
Stefan Armonat \& Andreas Pfnuer
}

First version: April $15^{\text {th }} 2003$. This version: May $12^{\text {th }} 2003$

Stefan Armonat, Senior Manager for Real Estate Finance, Eversmann \& Partner, Corporate

Real Estate Consultants; Research project "Property Investment in Germany"; e-mail: s.armonat@eversmann-und-partner.de

PD Dr. Andreas Pfnuer, Associate Professor for Real Estate Business Administration and Construction Management, TU Darmstadt; e-mail: pfnuer@bwl.tu-darmstadt.de. 


\title{
Asset allocation versus entrepreneurial decisions in real estate investment
}

\begin{abstract}
:
Although the application of capital market theory is questionable in real estate investment, many institutional investors still perform asset allocation with historic real estate data. Entrepreneurial investment analysis relies on a different information setting. To date it is unclear which approach, or what data set, offers the most efficient solutions for the use of capital. In order to evaluate policy recommendations for decision making in pension fund real estate investment, we describe an empirical investigation of the investment environment in Germany.

We find that current market information restricts the application of capital market models. While the use of investment models and capital market models has been strictly separated, there is no theoretically justified reason for this. Investors have to be aware that they can determine performance parameters for real estate only as approximations. Therefore, it may be fruitful to consider and compare alternative parameter estimates for determining optimal real estate allocations in pension fund investment.
\end{abstract}




\section{Asset allocation versus entrepreneurial decisions in real estate investment}

Institutional investors keep a significant portion of their overall asset holdings in real estate. More importantly, pension funds as the largest group of investors have a well documented interest in linking the characteristics of property investment with their specialized task and the objective of securing the pension payments to their members. But, in contrast to stocks and bonds, in property investment portfolio managers must deal with certain aspects of real assets, which affect the possibilities for allocating and switching these assets.

Decentralized market structures, difficult market entry and high transaction costs, illiquid markets and long-term execution of transactions, and a low level of public information characterize the imperfections of real estate markets. Due to specialized forms of performance evaluation and the need to manage an investment property, the return series cannot be determined analogous to stocks or bonds. As a result, the information content from real estate return series may vary in comparison to those taken from securitized assets.

If the portfolio manager of a pension plan sets up an optimization framework for the overall portfolio allocation, he will usually apply capital market models based on the Modern Portfolio Theory (Markowitz [1952]). The foundations of these models support him in simplifying a complex investment universe. Restrictive assumptions on the information efficiency of the market, the way prices are settled, individual rationality in investment decisions, and the resulting return distributions make it possible to draw simple conclusions on the financial advantage when an investor devotes capital to an asset. ${ }^{1}$ More than for any other asset class, there seems to be a consensus that these restrictions are not appropriate for real estate assets. ${ }^{2}$ Anecdotal evidence appears to declare real estate markets as inefficient. ${ }^{3}$ 
That is why the application of capital market theory to existing real estate data is questionable.

However, a portfolio manager will still be tempted to use historic return data on which he had applied a perfect mathematical analysis in his allocation efforts. But if the single model parameters do actually reflect irregular information contents, it is important to understand what effect different quality levels for return data will have on the outcome of the computation. An investor needs to take into consideration that prices in heterogeneous asset classes comply with model assumptions to varying extents. If he ignores this fact, he could be exposed to biased decision components. In this case, simultaneous modeling of real estate return series and return series on securitized investment vehicles may result in spurious recommendations for asset allocation and an inefficient use of capital.

With reference to the investment behavior of German institutional real estate investors, we will discuss whether the result of current investment decision making is an evaluation process that is capable of creating efficient return data for real estate on the market level. By relying on this decision process, conclusions can be drawn as to how the application of capital market theory on direct real estate investment would affect the quality of capital allocation recommendations in Germany.

We stress that investment analysis and capital market theory have the same foundations and can be transformed into each other; but, there is a considerable discrepancy in the application and the literature related to these decision making approaches. Therefore we emphasize that the break of models does not exist in theory, but in the use and the information setting included. After presenting empirical results, we will be in a position to compare survey interpretations with different investment decision models. This comparison will raise questions on policy implications for the use of optimal decision making tools in determining capital allocations to real estate in pension investment. Alternative decision models and a 
comparison of their results under particular decision circumstances contribute to an improved evaluation of real estate risk positions and can lead to more efficient allocations in real estate.

\section{Fundamental investment choice in real estate}

The elementary decision problem a portfolio manager has to solve is to choose optimal future cash flows for one of today's investments. Therefore he calculates the present value $P V$ of the expected future cash flows for every investment vehicle:

$$
P V=\sum_{i=1}^{n} \frac{C F_{i}}{(1+r)^{i}}
$$

Both the expected cash flows $C F$ and discount rates $r$ are uncertain at the time of investment. A first intuitive way of filling equation (1.1) with data is to gather information about possible and probable realizations of the cash flow values $C F$ in future periods. Decision makers often identify return factors that help to explain the development of a variable over time. This leads - either explicitly or implicitly - to probability distributions of the relevant return value. In this model, the discount rate reflects the individual attitude of a single investor towards the risk he perceives from the future realizations of the return values expected. Real estate investment analysis suggests extensive methods to collect and to condense the appropriate information set for the determination of the present value in a property investment decision. ${ }^{4}$

\section{Decision criteria from the entrepreneurs' point of view}

In the first instance, a definition of the relevant cash flow streams converts a theoretical formula into an applied decision instrument. Income streams depend on the amount of rents and property sale values, whereas the current cost expenditure relates to the equipment, the construction, and the age of the building. If an investor evaluates his expectation on the future cash flow, he will analyze regional economic influences to determine supply and demand for rental space, and as a consequence the resale value of a property at a certain point in time. 
Technical evaluation of the property and pragmatic values indicate the expected cash expenses. Sensitivity analysis, scenario modeling, or safety margins provide tools to estimate a risk range for the investment. In relation to the risk amount he will choose his specific discount rate. With this information he has a set of information available that returns a present value $P V$ for an individual property investment project.

\section{The market approach to real estate investment}

Individual assumptions and estimations make a comparison of different assets very difficult; first, there is an estimation difference for a single asset among different investors, and second, there is an evident need to contrast the financial effectiveness of two different assets with regard to an optimal capital allocation. In capital market theory the return characteristics of an asset are reduced to the mean and the standard deviation of its expected return. Under the assumptions mentioned above, it is sufficient to evaluate how a systematic risk component of an expected return contributes to the expected market return.

If the capital market is in equilibrium this approach replaces the repeated paired comparison of all single assets. Expected returns reward systematic risk taking. Here, the discount rate reflects an objective value for the relative risk amount of an asset in the capital market. The application of capital market theory relies in general on historic time series data. The main challenge in using capital market models for real estate is the estimation of model parameter (mean, standard deviation, correlation) from representative time series data on real assets. ${ }^{5}$

Mathematical and statistical analysis of past return data does not only cover the identification of an expected rate of return and the risk it is exposed to. As a central feature, the model relies on the cross-correlation of returns between different assets. Modern Portfolio Theory and all subsequent argumentation on risk diversification is based on these covariance matrixes. Assumptions postulate that it is possible to determine meaningful risk co-dependencies 
between assets and assets classes. Accurate determination of these parameters that do not relate only to independent projects is peculiar to capital market theory. While investment analysis gives statements for the independent value of idiosyncratic investment projects, capital market theory identifies an optimal combination of assets in the investment portfolio.

To simplify the investment choice into this model, the crucial question to answer is whether the asset prices identified in the market truly reflect the rational expectations of all investors. Capital market theory does in fact suggest that model parameters therefore need to be set up as "future values". Hartzell and Webb [1988], for example, estimate real estate parameters from future expectations gained by questioning property investment decision makers. They see the use of historical data for parameter estimation as pseudo accuracy. But even if academics cannot rule out the possibility of flawed historical real estate performance data, an extensive discussion in the literature on real estate asset allocation builds on this data as rational price proxies.

Common sources of market information on real estate performance are real estate indices. Based on exploratory work by Geltner [1991, 1993], academics developed statistical methods to unsmooth the underestimated risk parameter in appraisal based time series. Lai and Wang [1998] claim that these are intuitively appealing but they appear as ad-hoc adaptations that lack their theoretical foundation. Transaction based indices usually suffer from a small population of transaction data and biases in the data selection. ${ }^{6}$ Neither appraisal based indices, nor transaction based indices for unsecuritized real estate reveal the potential to estimate returns and in particular risk parameters (variances and covariances) accurately.

These irregular estimations become effective in the recommendations on optimal real estate portfolio contributions to mixed asset portfolios. On the one hand, calculated optimal holdings were fluctuating and slowly decreasing with the upcoming recovery ${ }^{7}$ of the risk dimension to real estate performance measures (Sirmans and Sirmans [1987] and Norman, Sirmans, and 
Benjamin [1995]); on the other hand, even today's estimates for real estate exceed with $7-9$ $\%$ the actual average holdings in pension funds of approximately $3-4 \%^{-8}$

These obvious insufficiencies in the explanatory power of real estate allocations led to statistically improved analyses. A sophisticated example is the latent-variable method suggested by Ling, Naranjo, and Nimalendran [2000]. All efforts in real estate market performance valuation relate to the goal of using an overlapping decision environment in institutional investment. Still, elementary questions on the justification of asset allocation efforts in real estate investment remain unsolved when mechanisms to identify model parameters are not consistent.

\section{Decision organization in institutional real estate investment}

We have outlined that the benefit from an integration of real estate into capital market models is a consistent valuation for the trade off between return and risk in capital allocation. Therefore, despite criticism in theory ${ }^{9}$, institutional investors apply capital market models in practice. In this context, Bajtelsmit and Worzola [1995] describe that investors perform asset allocation by asset classes first. Then, they select individual assets to achieve an optimal composition within a single class. That means when investors decide to dedicate capital to an asset they do not compare the systematic risk component of this asset with the total market risk; instead they benchmark a peculiar asset against a sub-index that incorporates the systematic risk of the relevant asset class. This behavior illustrates an adjustment of theory to the practical challenges of the real world.

But if the aim of capital allocation is to have a consistent methodology, these proceedings are not suitable for maintaining a common decision environment. Within-real-estate investment decisions then deviate from stock and bond allocations. Whereas portfolio managers in security investment have factors available that link the asset risk to market risk ( $\beta$-factors), 
similar values have not been calculated successfully for single properties. The decision for or against a property investment remains based on investment analysis tools.

Even if there is a justified real estate benchmark, only the identification and plausible interpretation of risk relations from the asset level to the market level would enable the investors to compare their holdings with this performance benchmark. The subsequent conclusions from an empirical survey will evaluate the preconditions to allocate real estate capital in Germany. From the survey results we will propose guidelines for the detection of accurate real estate performance data to compare it with information from other asset classes.

\section{Investment behavior in German direct real estate investment}

\section{Setting of a complete survey of real estate decision makers}

The objective of the empirical study conducted in spring 2001 was defined so as to shed light on causes and structure of risk, on performance valuation, and investment decision making in German real estate investment. It was a complete survey of the institutional real estate investment community in Germany; as the number of players is small, we distinguished 8 segments that perform institutional real estate investment: ${ }^{10}$ open-ended real estate funds, closed-ended funds, publicly traded real estate companies, insurance companies, pension funds, corporate real estate managers, developers, and private real estate investors. An unexpectedly high participation rate in the telephone survey of over $45 \%$ (91 out of 195 portfolio managers) proves the relevance of this topic for the institutions. The respondents manage approximately two thirds of the total real estate investment in Germany per annum. ${ }^{11}$ So, conclusions from the behavior of this group are highly relevant as they describe the conduct of a dominating investment group whose actions determine market movements.

Our survey tried to identify causal relations in the emergence of real estate return and risk from the estimations of the portfolio managers. Furthermore, it is in keeping with the tradition 
of empirical studies that investigate real estate investment decision making in other countries. ${ }^{12}$ As our objective in this article is descriptive, we will present selected results from the study report ${ }^{13}$ to give a picture of what the real estate investment environment is. The subsequent section does not contain statistical tests of hypotheses. We will contrast performance valuation behavior and decision practices in real estate with an idealized world of capital market models.

\section{Survey results}

\section{Risk estimation and predictive ability of real estate return factors}

The decision makers had to state what determinants they estimate to be of particular importance for the success of a real estate investment. A factor analysis (see Exhibit 1) of the items gives insight into the decision structure. After decades of financial research in real estate, the location of a property is still responsible (6.39 from 7) for the investors' perception of the success. Beyond this golden rule of real estate investment, the respondents try to evaluate the financial cash flows that are specific to property (initial investment value, potential sales price, income, and expenses).

Insert Exhibit 1 about here

But in contrast, economic development is a separate factor that only has an intermediate relevance of 4.81 for investment success. Looking at this information, it is evident that the property and its direct environment have a significant impact on the performance. Macroeconomic influences are only regarded as a whole. It is interesting to see that investors do not even separate inflation as a single item, as a lot of research has been done on real estate as an inflation hedge in a mixed asset portfolio. 
The single determinants influence each other and affect the investment return as a whole. Interdependencies between return factors reinforce undesirable trends and may lead to misjudgments in forecasting.

Insert Exhibit 2 about here

Exhibit 2 describes the interrelation of financial return determinants as portfolio managers perceive it. The analysis in particular stresses the correlation between rental income and sales price (6.5), rental income and acquisition cost (6.2), and maintenance expenses and sales price/rental income (5.1/5.2). It gives an explicit structure for further causal investigation of return generating processes.

\section{Performance evaluation ability}

German investors admit that they have little knowledge of the development of the factors they estimate as central for the cash flow projection on a ten-year horizon (see Exhibit 3). Their individual ability to guess the rental income ten years from today shows a deviation of $38 \%$ from the mean. With $86 \%$, rental income has the greatest impact on investment performance, followed by provisioning costs with $74 \%$, and the sales price with $66 \%$. The expenses for the construction of a building can be estimates with $38 \%$ deviation. The highest level of uncertainty exists for the achievable sales price in ten years $(47 \%)$.

Insert Exhibit 3 about here

At the same time, investors do not use methods that integrate the two dimensions of the decision problem. Only $21 \%$ of the decision-makers think that risk-utility analyses are suitable to handle the uncertainty of their investments. And only $8 \%$ of the decision-makers think that probability distributions are the best instruments for including risk perceptions into the calculation of the investment. A minority of the respondents only accepts more applicable methods such as scenario analyses (37\%) and discounts or supplements for risk (29\%). 
Portfolio managers do not take these risks into account because they do not see an opportunity to change their decisions after they have completed the investment. In their opinion, $65 \%$ of the investment success is already determined at the time the investment is made. Thus, investors do not keep an eye on the risk level because they do not feel free to switch to alternative projects after the investment has been made.

Alternatively, investors could calculate the historic risks of their property. Real estate decision-makers refuse to use this opportunity. Their view is future oriented. $2 \%$ of the respondents only use historic return data for an investment decision, whereas $51 \%$ think that only expected returns are a relevant measure $(47 \%$ prefer future data, but also look at historic data). Taking the insufficiency and infrequency of performance evaluation, we must assume that the investors do not have the right instruments available to determine and control the risk and return to their portfolio investments.

\section{Reactions to market perceptions}

Investors seek to structure or maybe diversify risk by splitting their investments between a variety of properties. The most relevant factors for allocation are the micro-location (77 \%) and macro-location $(68 \%)$. The decision-makers prefer regional diversification criteria to economic criteria. The most important economic factor is the object category that is mentioned by $58 \%$ of the respondents. Property size is only recommended by $33 \%$. For a diversification of risk, these factors appear to be more a naive strategy than a planned allocation.

Real estate decision makers themselves see great difficulties in constructing financially efficient real estate portfolios. Interestingly, they do not view the transaction costs and taxes as having a strong impact on market inefficiency (only $22 \%$ ) but rather the micro-market determinants. $53 \%$ think that information asymmetries and insufficient knowledge about the 
development of the markets cause the allocation failure to a great extent. $38 \%$ say individual expectations on performance are of high relevance for the inapplicability of financial asset pricing. A significant problem is the inseparability of real estate assets. $40 \%$ of the respondents see the individual impact of the single property as too important for portfolio performance. And again, the investors state that they invest for the long run. $49 \%$ say that since they do not switch portfolio holdings, they are not able to adapt to the changing market environment and keep the portfolio at an efficient composition.

\section{Interpretation of portfolio managers'statements}

For the context of our investigation we can interpret and summarize the findings about the real estate investment decision behavior as follows:

- The German market for real estate investment seems to be information efficient and allocation efficient only to a quite low degree.

This is the case because investors disregard economic information that is elementary for the development of demand and supply. They concentrate on property categories they have experience with and rely on an analysis of object criteria and of the micro environment. They act under complete consciousness of inefficient market allocations and therefore employ private information.

- Risk valuation tools in real estate investment appear to be unsatisfactory; performance data relying on this information must be treated with caution.

Portfolio managers neither demonstrate the ability to estimate future performance determinants accurately nor do they estimate historic performance valuations as relevant for their current investment decisions. Comparability of the performance estimates is restricted because of an uncertain shape of the risk dimension. 
- We must understand real estate portfolio management more as a qualitative, strategic process than as a closed financial construction.

Portfolio managers perceive the market frictions as significant for preventing them from constructing financially efficient portfolios. They lack trust in the ability of indices or especially sub-indices to evaluate alternatives. Instead, they choose qualitative criteria and peculiar property characteristic as indications for successful investments.

- Real estate specific return determinants have a high relevance for the success of an investment project; intuitively, causal relations strongly influence performance valuation and real estate decision making.

Investors base real estate investment decisions on a complex structure of return generating factors. They estimate risk factor codependences individually and heterogeneously and focus on the actual decision alternatives. We must expect resulting return distributions to be related to the distributions of the original return factors.

This summary makes clear that unsecuritized real estate does not represent financial assets in their genuine meaning. Though the background of a capital attribution to real estate is capital investment, the necessity of an operative investment management and controlling is not separable from the property investment activities.

\section{Appropriate tools for optimal real estate investment}

\section{Comparing model assumptions to the investment environment}

The deductions from the empirical survey oppose the necessary assumptions for an application of capital market models to real estate investment decisions.

- Even applied investment analysis tools neglect information on return development, risk causes, and financial data relevant for a reliable ex-post investment evaluation. As a 
consequence, the returns identified do not incorporate all available market information. Market indices that use this return information as fundamental time series data are probably biased towards lower risk estimates. Therefore, current real estate market data does not reflect the true performance characteristics for asset allocation.

- It is difficult to expect returns in complex property investment projects as if they are perfectly normally distributed. This characteristic makes a separation of systematic and idiosyncratic risk elements virtually impossible. Property specific risk influences probably dominate market risk movements. Then, portfolio risk diversification is difficult to achieve and simple, single dimensioned risk relations to determine risk co-dependencies become obsolete.

In the current German investment environment for real estate, investment decisions based on asset allocation recommendations do not seem to cover all necessary aspects of the capital use. The investor probably underestimates the risk to return relation of the investment and trivializes the actual decision problem.

These findings are no proof against a general use of real estate data in capital market models. Describing a development path for real estate allocations will be a very important and challenging task to the real estate community - in Germany and internationally. But if the allocation recommendations have to reflect the real opportunity cost of capital, then practitioners and academics have to develop parameters that come closer to the true riskreturn relation the institutional real estate investor is exposed to.

Real institutional investors still perform real estate investment decisions on the same level as stock and bond investment. However, we must investigate decisions for unsecuritized real estate separately. The main reason for that is a high relevance of the property structure for the success of the investment project. Causal interrelations from real world economics evoke complex return distributions. Moreover, the reversibility of the investment decision is limited. 
Investors will value different degrees of flexibility. At the same time, while the investment universe in real estate is enormous, the investment alternatives are restricted by regional constraints and the supply of property. Investors have advantages in comparing definitive investment opportunities. And, in the end, they will continue to consider the long term engagement with a property and individual demand functions over the investment horizon.

The difference to capital market securities is significant. Considerations on descriptive performance evaluations have to take these elements into account. Real estate will remain an entrepreneurial investment with operational risk characteristics to it. Because real estate investment analysis has few restrictions and shows the flexibility to include individual aspects of an investment project, alternative parameter estimation could rely on these models. An adapted use and the appropriate extension of investment tools will help in the discovery of performance parameters for distinctive real estate portfolios. Investors may use these individual real estate parameters as substitute proxies for the comparison of real estate investment to other asset classes.

As Holland, Ott, and Riddiough [2000] put it, investment models take different approaches to evaluate the risk inherent to the investment. With the experience from the real estate investment environment we see that there need to be strong efforts in theory and practice to combine results from capital market models and the predominant investment analyses. Under their specific objectives and assumptions, both approaches have their justification for real estate decision making and performance measurement. But, with the restrictions on real assets, investors must treat both results with care and interpret them considerably.

\section{Alternative approaches to real estate investment parameter estimates}

Micro-econometric models have the potential to explain complex causal structures in real estate investment. With generally accepted modeling principles and common data sources for 
submarkets it will be possible to raise the information level in real estate markets. Based on this, an improved investment model must be chosen. While the identification of discount rates from capital market models is very complex for real estate investment, simple scenario analyses or safety margins on present values - that are applicable in the investment setting result in recommendations of insufficient quality.

Investors need to broaden their project analysis tools to calculate complex relations with heterogeneous data distributions. With modern computer technology they can gain plausible return distributions for investment projects especially as the number of decision alternatives is limited in real estate investment. In some cases, portfolio managers may have the need to extend the modeling to an application of real option theory in real estate investment. ${ }^{14}$ From the return distributions and the option values they would be able to determine expected returns and risk parameters as values-at-risk or variances.

Parameters from such computation have their limitations. In no way do they have the accuracy or the objectivity of security data collected on the market level. They are individual estimates of peculiar real estate portfolio compositions. Small changes or inaccuracies in the original data set may lead to extreme variations in parameters. But all statistical analysis, including capital market valuation of assets, is subject to these pitfalls. Hand picked performance parameters may not look as sophisticated, but they probably incorporate a more accurate performance description of real estate than one can gain from flawed real estate time series data.

The main point is that academics need to show real estate investors who act in a specialized market environment the way so that they can link real estate into capital market optimizations. A pure transferal of methods applied in security analysis identifies parameters, but the validity of these variables is highly questionable looking at the empirical description of the investment environment. Individual investment analysis tools will help to investigate the soundness of 
historical parameter computations. Finally, the investor will have to trade off the alternative results that he has extracted from his information basis. The better capital market models and real estate investment analysis reflect the special decision environment in real estate, the less random the subsequent asset allocation recommendations will be.

\section{Summary}

This investigation has been set up to identify the institutional real estate investment environment from current real estate investment behavior. It discusses whether real estate asset allocation decisions from historical time series data lead to an efficient use of capital in Germany. The results show clearly that institutional investors can not treat real estate like securities. Asset allocation based on historic time series data appears to be imperfect and fund managers lack the ability and information to adjust their own portfolio to market risk perceptions.

For the important task of including unsecuritized real estate into allocation considerations, investors need to accept that they can not approach the true opportunity cost of capital with complete accuracy. Although capital market theory and investment analysis relate to particular information sets in practice, in real estate investment it appears fruitful to bring use and data concerning these models closer together. Further research needs to investigate the microeconomic basis of causal real estate risk and return structures, a common data model with consistent data availability on the sub-market level, and finally, a comprehensive investment model that increases the objectivity of investment calculations. Only a sensible comparison of results from alternative investment models has the potential to identify more realistic real estate performance estimates for capital allocation. 


\section{Exhibit 1: Decision criteria for real estate investment projects}

\begin{tabular}{|c|c|c|c|}
\hline Factors & Related items & Relevance $^{\dagger}$ & Std.dev. \\
\hline location & quality of location at construction or acquisition & 6.39 & 0.90 \\
\hline provisioning of property & building cost/acquisition cost, substance of buildings & 5.83 & 1.42 \\
\hline sales price & attainable sales price & 5.67 & 1.65 \\
\hline $\begin{array}{l}\text { marketability of real } \\
\text { estate (income) }\end{array}$ & $\begin{array}{l}\text { tenant credit-worthiness, initial tenant-mix, appearance, rental } \\
\text { income, quality of facility management }\end{array}$ & 5.65 & 0.81 \\
\hline $\begin{array}{l}\text { cost effectiveness of } \\
\text { real estate (expenses) }\end{array}$ & $\begin{array}{l}\text { management fee, maintenance costs, cost of operation, } \\
\text { building efficiency, utilization flexibility, contract design }\end{array}$ & 4.92 & 1.60 \\
\hline capital market yields & yields of alternative investments & 4.84 & 1.84 \\
\hline economic environment & $\begin{array}{l}\text { regional economic growth, inflation, macroeconomic growth, } \\
\text { regional socio-demografics, regional real estate market } \\
\text { conditions, infrastructure }\end{array}$ & 4.81 & 1.12 \\
\hline cost of equity & calculatory equity yields & 4.59 & 1.90 \\
\hline real estate finance & $\begin{array}{l}\text { debt yields, capital structure, tax amount, tax environment, } \\
\text { capital market yields }\end{array}$ & 3.78 & 2.18 \\
\hline
\end{tabular}

$\dagger$ : Mean of respondents' estimates; noted on a scale from 1=unimportant to $7=$ very important.

Source: Pfnuer and Armonat [2001] 
Exhibit 2: Interdependency ${ }^{\dagger}$ of financial return factors

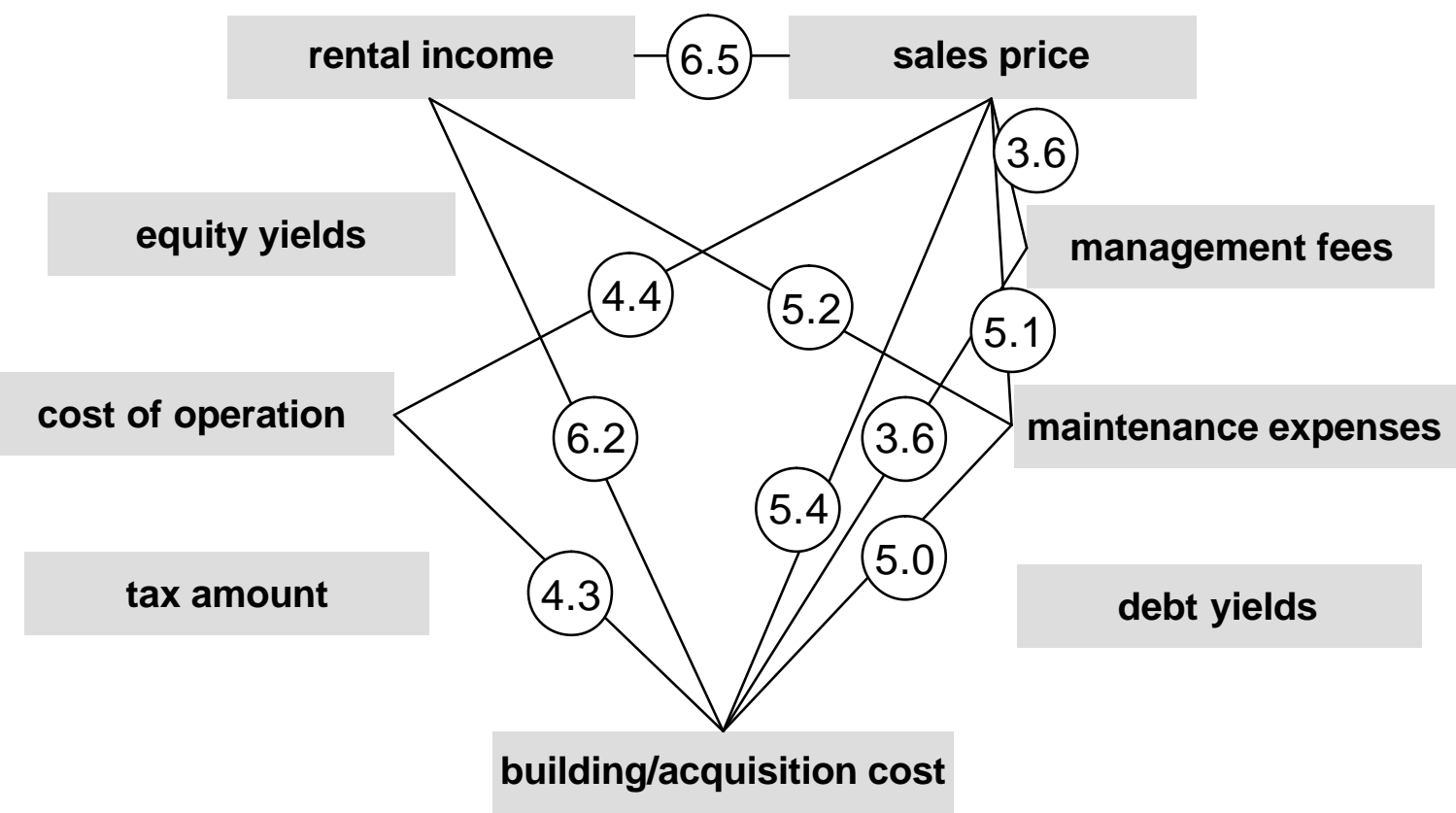

$\dagger$ : Mean of respondents ${ }^{\prime}$ correlation estimates; noted on a scale from $1=$ unimportant to $7=$ very important.

Source: Pfnuer and Armonat [2001] 
Exhibit 3: Relevance and estimation accuracy of return factors

\section{Relevance of return factors affecting payment \\ High relevance for investor}

Accuracy to predict financial influences

Forecasting uncertainty for investor $\dagger \dagger$

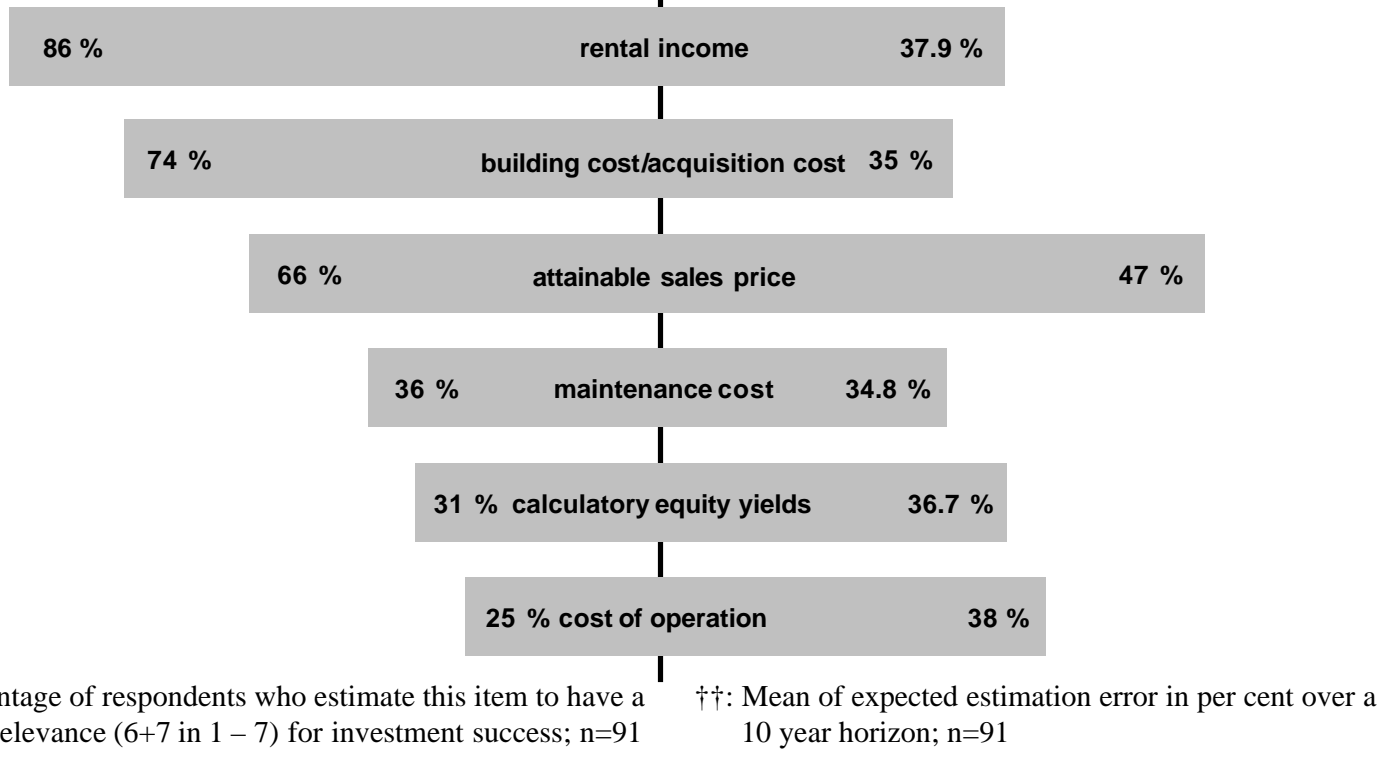
10 year horizon; $n=91$

Source: Pfnuer and Armonat [2001] 


\section{Endnotes}

${ }^{1}$ For a detailed discussion of the assumptions in capital market models, especially for the CAPM, see for example Fama and Miller [1972], pp. 276-279.

2 Compare Young and Graff [1995], Pagliari, Webb, and Del Casino [1999], Fu and Ng [2001], and Young and Annis [2002] who question the applicability of capital market theory on real estate investment.

${ }^{3}$ Gatzlaff and Tirtiroglu [1995] present an extensive survey of investigations on real estate market efficiency. They conclude that no final judgement on real estate market efficiency is possible. But generally, the degree of market efficiency has to be estimated quite low.

${ }^{4}$ Detailed descriptions of relevant aspects in real estate investment analysis are presented in Phyrr and Cooper [1991], Jaffe and Sirmans [1995], and in Brueggeman and Fisher [1997].

${ }^{5}$ Ross and Zisler [1991] discuss what sources are available for real estate time series data.

${ }^{6}$ Fisher, Geltner, and Webb [1994] describe these challenges for the construction of a reliable real estate performance measure.

7 Academics applied statistical methods to „recover“ the second argument of real estate time series analysis; the variance had been perceived as being underrepresented in the performance estimates; the aim was to reduce this appear ant "smoothing". See for a description Corgel and deRoos [1999].

${ }^{8}$ Ciochetti, Sa-Aadu, and Shilling [1999] present this relation as they discuss institutional reasons for lower real estate holdings.

${ }^{9}$ A compilation and evaluation of approaches that criticize central assumptions or the consequences from an application of the CAPM in capital markets can be found in Campbell [2000], pp. 1527- 1529.

${ }^{10}$ As the number of players is small compared to the US, in addition to property only investors, we included all institutional groups that perform institutional real estate investment.

${ }^{11}$ Because of the high relevance of risk management for large institutional investors, more of these decision makers replied than those from small investors. By calculating the average annual investment volume indicated for each group, we were able to asses quite accurately the overall investment size that we cover with the survey.

${ }^{12}$ Farragher and Kleinman [1995] offer a comprehensive review of these papers.

${ }^{13}$ We give a complete description of the survey methodology, the results, and basic interpretation in a report: Pfnuer and Armonat [2001].

${ }^{14}$ Real option models have been applied to real estate investment decisions; see for example Grenadier [1995] or Schaefer and Pfnuer [2000].

\section{References}

Bajtelsmit, Vickie L. and Elaine M. Worzola. "Real estate allocation in pension fund portfolios.” Journal of Real Estate Portfolio Management, 1 (1) (1995), pp. 25-38.

Brueggeman, William II. and Jeffrey D. Fisher. "Real estate finance and investments." $10^{\text {th }}$ ed., Chicago, Irwin, 1997.

Campbell, John Y. “Asset pricing at the millennium.” Journal of Finance, 55 (4) (2000), pp. 1515-1567.

Ciochetti, Brian A., Jarjisu Sa-Aadu, and James D. Shilling. "Determinants of real estate asset allocations in private and public pension plans.” Journal of Real Estate Finance and Economics, 19 (3) (1999), pp. 193-210.

Corgel, John B. and Jan A. deRoos. "Recovery of real estate returns for portfolio allocation.” Journal of Real Estate Finance and Economics, 18 (3) (1999), pp. 279-296.

Fama, Eugene F. and Merton H. Miller. “The theory of finance.” New York et al., 1972. 
Farragher, Edward J. and Robert T. Kleinman. "A re-examination of real estate investment decisionmaking practices.” Journal of Real Estate Portfolio Management, 2 (1) (1996), pp. 31-39.

Fisher, Jeffrey D., David M. Geltner, and Brian Webb. "Value indices of commercial real estate: a comparison of index construction models.” Journal of Real Estate Finance and Economics, 9 (1994), pp. 137-164.

Gatzlaff, Dean H. and Dogan Titriroglu. “Real estate market effic iency: issues and evidence.” Journal of Real Estate Literature, 3 (1) (1995), pp. 157-189.

Geltner, David M. "Smoothing in appraisal-based returns." Journal of Real Estate Finance and Economics, 4 (1991), pp. 327 - 345.

Geltner, David M. "Estimating market values from appraised values without assuming an efficient market." Journal of Real Estate Research, 8 (3) (1993), pp. 325-345.

Hartzell, David J. and James R. Webb. "Real estate risk and return expectations: recent survey results." Journal of Real Estate Research, 3 (3) (1988), pp. 31-37.

Holland, A. Steven, Steven H. Ott, and Timothy J. Riddiough. "The role of uncertainty in investment: an examination of competing investment models using commercial real estate data." Real Estate Economics, 28 (1), pp. 33-64.

Jaffe, Austin J. and C.F. Sirmans. "Fundamentals of real estate investment.” $3^{\text {rd }}$ ed., Englewood Cliffs, 1995.

Lai, Tsong-Yue and Ko Wang. “Appraisal smoothing: the other side of the story.” Real Estate Economics, 26 (3) (1998), pp. 511-535.

Ling, David C., Andy Naranjo and M. Nimalendran. "Estimating returns on commercial real estate: a new methodology using latent-variables models.” Real Estate Economics, 28 (2) (2000), pp. 205-231.

Markowitz, Harry M. “Portfolio selection.” Journal of Finance, 7 (1) (1952), pp. 77 - 91.

Norman, Emily J., G. Stacy Sirmans, and John D. Benjamin. "The historical environment of real estate returns." Journal of Real Estate Portfolio Management, 1 (1) (1995), pp. 1-24.

Pagliari, Joseph Jr., James R. Webb, and Joseph J. Del Casino. “Applying MPT to institutional real estate portfolios: the good, the bad, and the uncertain." Journal of Real Estate Portfolio Management, 1 (2), pp. 67-88.

Phyrr, Stephen A. and James R. Cooper. "Real estate investment - strategy, analysis, decisions." $2^{\text {nd }}$ ed., New York, Chichester, et al., 1989.

Pfnuer, Andreas and Stefan Armonat. „Immobilienkapitalanlage institutioneller Investoren - Risikomanagement und Portfolioplanung [Institutional real estate investment - Risk management and portfolio planning]. "Working paper No. 26 - April 2001, Research project: "Property investment in Germany" at the University of Hamburg. http://www.property-investment.de.

Ross, Stephen A. and Randall C. Zisler "Risk and return in real estate." Journal of Real Estate Finance and Economics, 4 (1991), pp. 175-190.

Schaefer, Christina and Andreas Pfnuer. "Evaluating corporate real estate with real options." OR Proceedings 2000, pp. 188-195.

Sirmans, Stacy and C. F. Sirmancs. "The historical perspective of real estate returns." Journal of Portfolio Management, Spring 1987, pp. 22-31.

Young, Michael S. and Susan Annis. "Real estate performance attribution: pure theory meets messy reality." Journal of Real Estate Research, 23 (1/2) (2002), pp. 3-27.

Young, Michael S. and Richard A. Graff. "Real estate is not normal: a fresh look at real estate return distributions." Journal of Real Estate Finance and Economics, 10 (2) (1995), pp. 225-259. 